\title{
제한된 보행패턴이 정상 성인의 심폐기능에 미치는 영향
}

\author{
이상설, 양경한, 박정서 \\ 대전과학기술대학교 물리치료과
}

The Effects of Restricted walking Patterns on Cardiopulmonary Functions of Young Adult

Sang-Seol Lee, Kyung-Han Yang, Jung-Seo Park*

Dept. of Physical Therapy, Daejeon Institute of Science and Technology

Purpose The Purpose of this study was to investigate the effects of additional limitations during walking on cardiopulmonary functions. The results can be used as basic value for studying of relative on lower extremity problem. Methods Ten healthy female college students, none of whom had gait abnormality, were participated in this experiment. Subjects walked on a treadmill at comfortable walking $\operatorname{speed}(3.62 \mathrm{~km} / \mathrm{h})$ under three conditions. Three conditions were First group is without a knee immobilized and crutches(N;normal gait), Second group is with a knee immobilized(C;cast), and Third with a knee immobilized and crutches(CC;cast+cruch). RER, VO2, Kcal, VE was measured by K4b2 and body composition by Inbody 570. The effect values were used mean value of that SPSS(ver. 18.0) in performance of all statistical analyses, statistical significance was set at 0.05 . Results Measures increased under three conditions, but significant differences existed in VO2, Kcal. Also, Significant differences existed in CC group compared with N group and $\mathrm{C}$ group. Conclusion Knee immobilization and using crutches increase energy expenditure during level walking at comfortable walking $\operatorname{speed}(3.62 \mathrm{~km} / \mathrm{h})$ than knee immobilization and normal. Therefore, This fact must be considered during gait training and exercise.

Key words Cardiopulmonary function, Energy consumption, Energy expenditure, Restrict walking

Corresponding author Jung-Seo Park ( pjs2015@dst.ac.kr)

Received date 22 May 2018

Revised date 04 June 2018

Accepted date 13 June 2018

\section{I. 서 론}

정상보행이란 잘 조화된 사지의 운동을 통해 최소한의 에너지 를 소모하면서 부드럽고 효과적으로 신체의 무게중심을 앞쪽으 로 이동시키는 것을 말한다. ${ }^{1)}$

일반적으로 정상인은 단위거리 당 소모되는 에너지를 최소 화하기 위한 보행방식과 속도로 걷는데, 이런 보행방식과 속도 를 벗어나게 되면 에너지 소모가 증가하게 된다. 때문에 장애 를 갖고 있는 환자가 정상인에 비해 더 많은 에너지를 소모하 게 된다고 할 수 있다. ${ }^{2)}$ 따라서 이러한 환자에게 치료적 운동 을 시키거나 보행훈련을 시킬 때도 에너지 소모에 많은 관심을 갖는 것이 필요하다.

보행을 하는 동안 에너지 대사와 밀접한 관련이 있는 조직 은 심폐계이다. 효과적이고 조화된 심폐계는 보행에 필요한 에

doi : http:dx.doi.org/10.17817/2018.06.04.111276
너지를 만들기에 충분한 양의 산소를 신체 조직에 공급하고, 조직에 쌓여 있는 이산화탄소를 제거하며, 다양한 대사요구에 적절하게 반응한다. ${ }^{3)}$

심폐계는 다양한 원인에 의해서 영향을 받지만 특히 운동 이 가장 흔한 생리적 자극제와 같다. 물론 운동의 강도에 따라 심폐계의 반응도 달라지게 된다. 때문에 이러한 반응의 결과를 측정하면, 환자의 기능적 능력을 평가할 수 있고, 질환의 진단, 예후 및 회복 정도를 예측할 수 있다. 더욱이, 치료의 효과를 평가하는데도 사용할 수 있고, 환자에게 적절한 운동치료를 처 방하는 기초를 얻을 수도 있게 된다.2)

심폐계에 영향을 줄 수 있는 요인으로는 신체에 부가되는 하중과 비정상적인 보행 패턴에서 생기는 부자연스러움을 들 수 있다. 때문에 산업재해와 교통사고 후의 보조기나 의지 착 용함으로 생기는 하중과 뇌혈관사고로 인한 편마비 환자의 비 정상적인 보행 패턴도 에너지 소모에 영향을 줄 수 있을 것이 다. 이러한 점들을 고려한다면 에너지 소모 정도를 측정하는 
것은 환자 치료에 많은 도움이 될 것이다.

에너지 소모량을 측정하는 방법으로는 산소소모량과 심박 수를 이용하는 방법이 있다. 그 중에서도 산소소모량을 이용하 는 방법은 다시 직접 측정방법과 간접 측정방법으로 구분된다. 이 중 간접 측정방법은 직접 측정방법에 비해 비교적 간단하고 경제적이면서도 그 측정 결과의 신뢰성이 높은 것으로 알려져 있다. ${ }^{4)}$ 간접 측정방법에는 다시 개방 회로법(open circuit method)과 폐쇄 회로법(closed circuit method)으로 나눌 수 있다. 두 가지 방법 중에서도 피험자가 대기로부터 공기를 들이마신 후 호기가스를 특정장치로 내쉬는 형태로 산소소모량 을 측정하는 개방회로법이 더 실용적이며 많이 쓰이고 있다.

본 연구는 이것에 기초해서, 보행시 정상적으로 일어나는 움직임들의 제한이 에너지 소모량에 어떤 영향을 줄 수 있는 지, 신체 동작시 부가되는 보조기의 무게가 에너지 소모에 영 향을 줄 수 있는지를 산소소모량을 이용한 개방회로법을 사용 하여 에너지 소모 정도를 측정하여 확인하고자 한다. 본 실험 의 결과는 장애가 있는 환자들에게 치료적 운동이나 보행 훈련 을 시킬 때, 에너지 소모를 줄이면서 효과적일 수 있는 프로그 램을 개발하기 위한 기초 자료를 제공하는데도 유용할 것으로 생각한다.

\section{II. 연구방법}

\section{1. 연구대상}

본 연구는 대전소재 대학에 재학중인 건강한 20 대 성인 중 연 구목적과 연구방법을 충분히 설명하고 동의한 남자 21 명을 대 상으로, 신경계, 근골격계, 심폐계의 과거병력 및 보행장애가
없는자로 하였다. 본 연구 목적에 동의하고 독립적으로 걷거나 이동하는 것이 가능하며 인지적인 문제가 있어 연구자의 지시 나 의도를 이해지 못하는 실험자를 제외하였다.

\section{2. 연구도구}

1) 체성분분석기

본 연구에 사용된 체성분분석기는 Inbody520(Biospace, Korea, 2015)를 사용하였다. 이 장비는 8점타식 저주파수 방 식으로 전류가 지방조직에서 잘 흐리지 않는 성질을 이용하여 팔과 다리 표면 전극을 이용하여 전기 저항을 측정함으로써 부 위별 체지방량과 제지방량, 분량을 측정하는 방법이다(Figure1).

\section{2) 가스분석기}

본 연구에 사용된 가스분석기는 K4b2(COSMED, Italy, 2009)를 사용하였다. 이 장비는 유량범위 0 20l/s, 환기 범위 $5 \sim 301 / \mathrm{m}$, 산소 $\left(\mathrm{O}_{2}\right)$ 7 24\%와 이산화탄소 $\left(\mathrm{CO}_{2}\right)$ 0 8\% 측정 가능하고, 16,000 회의 호흡을 측정할 수 있는 디지털화된 무선 가스분석 장비이다(Figure2).

\section{3. 측정방법}

보행제한에 따른 에너지 소모도를 알아보기 위해 대상자를 세 그룹으로 나누었다. 첫 번째 그룹(정상군)은 아무런 제한 없이 트레드밀 위에서 걷게 하였고, 두번째 그룹(석고고정군)은 무 릎관절에 대전자 아래에서 부터 발목까지 석고고정을 하고 걷 게 하였다. 세번째 그룹(석고목발군)은 석고고정을 하고 양손 을 사용하여 목발 보행을 하며, 이때 목발보행의 형태는 목발 이동 후 석고고정발을 내딛는 삼점 보행을 하였다. 이에 따라 21 명의 대상자들은 각각의 조건에 맞추어 3 번씩 실험을 하였

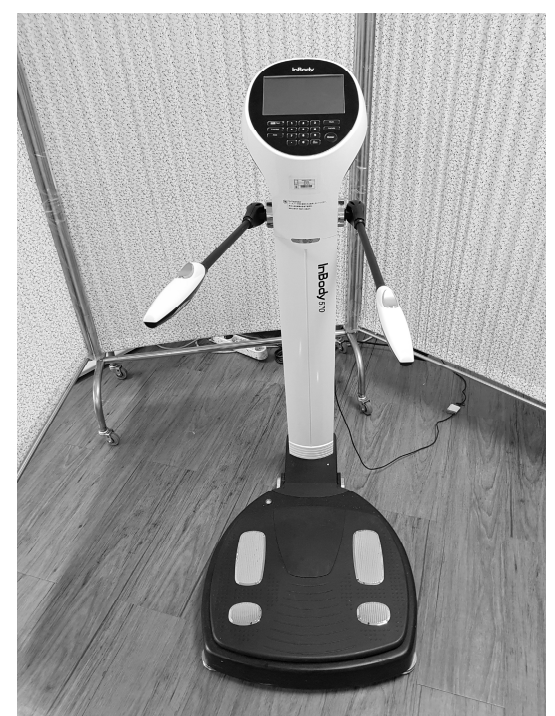

Figure 1. Bioelectrical impedance

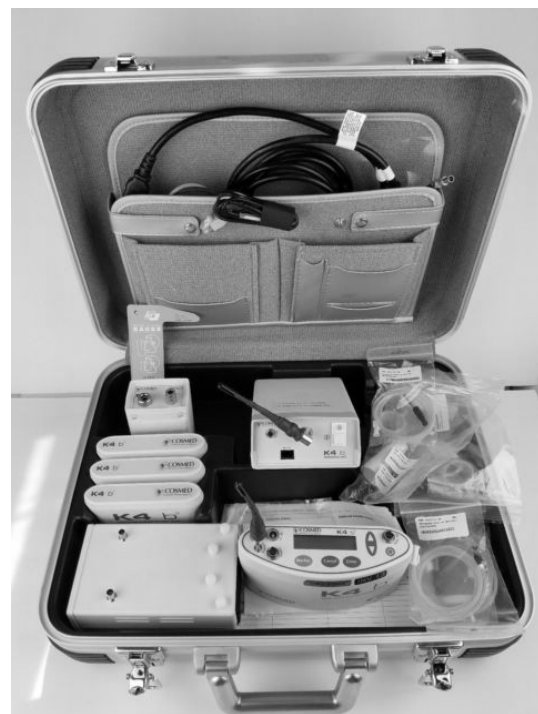

Figure 2. Metabolic system 
고, 측정값은 평균값으로 하였다. 석고고정은 각 대상자들에게 맞게 제작하였으며 무게는 평균 $1.8 \pm 0.41 \mathrm{~kg}$ 이였다.

실험을 실시하기 전 Inbody 570(biospace, korea)을 사용하여 체성분 분석을 하였다. 보행속도는 석고를 착용하고 트레드밀을 걷게 하여 편안하다고 느끼는 속도인 $3.62 \mathrm{~km} / \mathrm{h}$ 로 정하였으며, 이 속도는 세 가지 조건 모두 동일하게 적용 하였다.

호흡 가스분석을 위해 대상자들은 실험실에 도착하여 약 30 분 가량 안정을 취하였으며, 실험을 진행하기전 가스분석을 위해 마스크를 착용하였다. 복장은 편안한 차림에 운동화를 착 용하도록 하였다.

가스분석은 무선 호흡 분석기(COSMED K4b2, Italy)를 사용하였고, 총 20 분간 매 30 초 마다 호흡교환율(RER; Respiratory Exchange Rati), 산소소모량 $\left(\mathrm{O}_{2}\right.$; Oxygen Cost $)$, 소모칼로리(Kcal), 환기당량 $(\mathrm{VE} ;$ Ventilatory Equivalent)을 측 정하였다. 본 연구에서는 20 분중 각 2 분마다 측정값들의 평균 과 표준편차를 사용하였다. 각 대상자들은 한가지 조건의 실험 이 모두 끝나 뒤 일주일간 휴식을 한 후 그 다음 조건의 실험 을 진행하였다.

\section{4. 분석방법}

대상들의 일반적 특성은 동질성 검정을 하였으며, 각 조건에 따라 호흡교환율, 산소소모량, 소모칼로리, 환기당량을 비교하 기 위해 일원배치분산분석을 하였다. 또한 각 조건들 간의 차 이를 알아보기 위해 사후검정을 실시하였다. 각각의 측정결과 들을 통계프로그램인 SPSS(ver. 18.0)를 사용하여 분석하였으 며, 유의수준은 0.05 로 하였다.

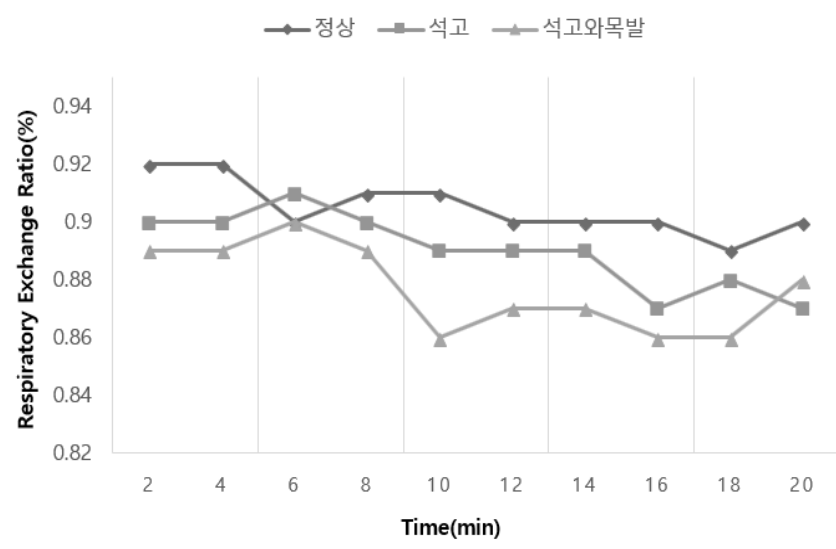

Figure 3. The changes of respiratory exchange ratio

\section{III. 연구결과}

\section{1. 그룹간 호흡교환율(RER)}

트레드밀에서 2 분간 걸은 후 호흡교환율은 정상군 $0.92 \pm 4.35$, 석고고정군 $0.90 \pm 6.43$, 석고목발군 $0.89 \pm 5.44$ 로 차이가 있는 것처럼 보이나, 통계학적으로 유의하지는 않았다.

트레드밀에서 20 분간 걸은 후 호흡교환율은 정상군 $0.90 \pm$ 3.75 , 석고고정군 $0.87 \pm 3.82$, 석고목발군 $0.88 \pm 2.54$ 로 통계 적으로 유의하지는 않았다(figure3).

\section{2. 그룹간 산소소모량( $\mathrm{VO} 2)$}

트레드밀에서 2 분을 걸은 후 산소소모량은 정상군 $10.26 \pm 5.87$, 석고고정군 $13.87 \pm 3.51$, 석고목발군 $18.56 \pm 2.78$ 으로 차이가 있었다 $(\mathrm{p}<0.05)$. 사후 검정 결과 정상군과 석고고정군에 비해 석고목발군의 산소소모량이 많았다. 트레드밀에서 20 분간 걸은 후 산소소모량은 정상군 $12.26 \pm 4.68$, 석고고정군 $12.88 \pm 3.89$, 석고목발군 $17.47 \pm 2.87$ 로 차이가 있었다 $(\mathrm{p}<0.05)$. 사후 검정 결과 정상군과 석고고정군에 비해 석고목발군의 산소소모량이 많았다(figure4).

\section{3. 그룹간 칼로리의 변화}

트레드밀에서 2 분을 걸은 후 소모된 칼로리량은 정상군 $3.12 \pm 2.01$, 석고고정군 $3.95 \pm 1.95$, 석고/목발군 $4.80 \pm 1.23$ 으로 차이가 있었다 $(\mathrm{p}<0.05)$. 사후 검정 결과 정상군과 석고 고정군에 비해 석고/목발군의 칼로리 소모량이 많았다.

트레드밀에서 20 분간 걸은 후 소모된 칼로리량은 정상군 $3.63 \pm 2.01$, 석고고정군 $3.42 \pm 1.64$, 석고목발군 $4.88 \pm 1.64$ 로 차이가 있었다 $(\mathrm{p}<0.05)$. 사후 검정 결과 정상군과 석고고정군 에 비해 석고목발군의 칼로리 소모량이 많았다(figure5).

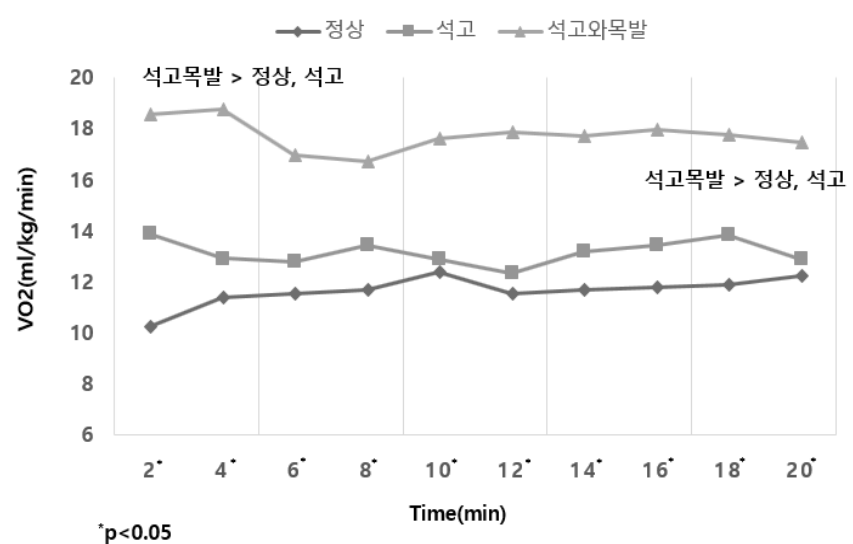

Figure 4. The Changes of V02 


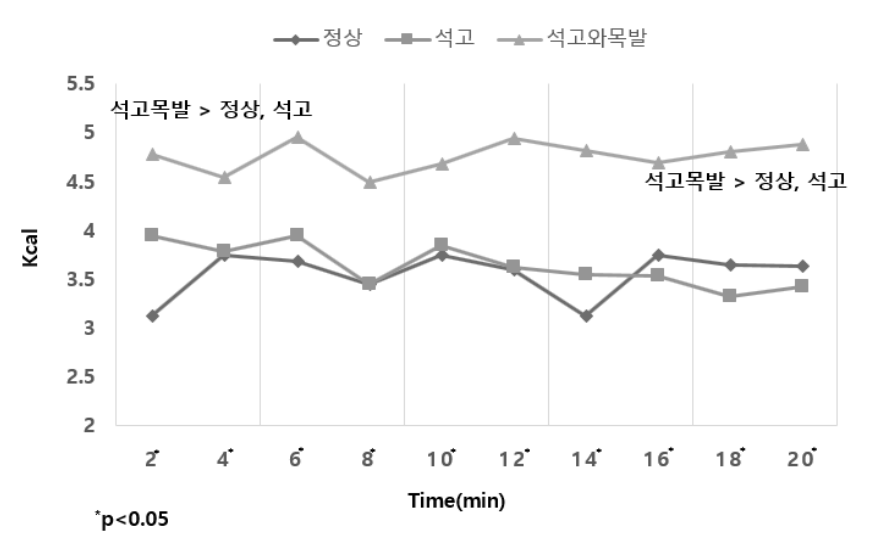

Figure 5. The Changes of Kcal

\section{4. 그룹간 환기당량(VE)}

트레드밀에서 2 분을 걸은 후 환기당량은 정상군 $1.72 \pm 0.36$, 석고고정군 $1.73 \pm 0.25$, 석고목발군 $1.72 \pm 0.29$ 로 차이가 있는 것처럼 보이나 통계학적으로 유의하지는 않았다. 트레드밀에서 20 분간 걸은 후 환기당량은 정상군 $1.80 \pm 0.19$, 석고고정군 $1.71 \pm 0.31$, 석고목발군 $1.78 \pm 0.26$ 로 차이가 있는 것처럼 보이 나 통계학적으로 유의하지는 않았다(figure6).

\section{IV. 고찰}

개인의 신체능력을 알아보기 위한 방법의 하나가 바로 운동시 나 활동시에 개인이 소비하는 에너지 소모량을 측정하는 것이 다. 에너지 소모량은 운동을 할 때 산소를 소비할 수 있는 능 력 즉 산소소모량을 측정함으로써 간접적으로 알 수 있으며, 산소소모량은 건강한 정상성인에서 체중, 성별, 신체적 활동능 력에 따라 다른 것으로 알려져 있다.5)

산소소모에 가장 큰 영향을 줄 수 있는 요인으로 보행속도 를 들 수 있는데, 연구자에 따르면 정상인에 있어서는 산소소 모율과 보행속도간에 통계적인 유의한 상관관계는 없었으나, 편마비 환자와 같은 경우에 있어서는 통계학적으로 유의한 순 상관관계를 보였다고 한다. ${ }^{\circ}$ 또한 보행속도가 증가함에 따라 정상인들에게 있어서도 에너지 소모도가 증가한다고 하였다. ${ }^{7)}$ 본 연구에서의 보행속도는 실험대상자들이 석고를 고정하고 트 레드밀 위를 걸어보게 하여 결정하였으며, 그 중 가장 편안하 다고 느끼는 속도인 $3.62 \mathrm{~km} / \mathrm{h}$ 로 결정을 하였다. 이는 조건 모두에 있어서 동일하게 적용하였다. 따라서 석고군이나 석고 목발군에 있어서는 제한이 있기 때문에 보행속도는 정상일 때 보다 상대적으로 빠르게 느껴질 것이며, 이는 앞에서 언급한 보행속도가 빨라지면 에너지 소모가 증가한다는 연구결과로 미

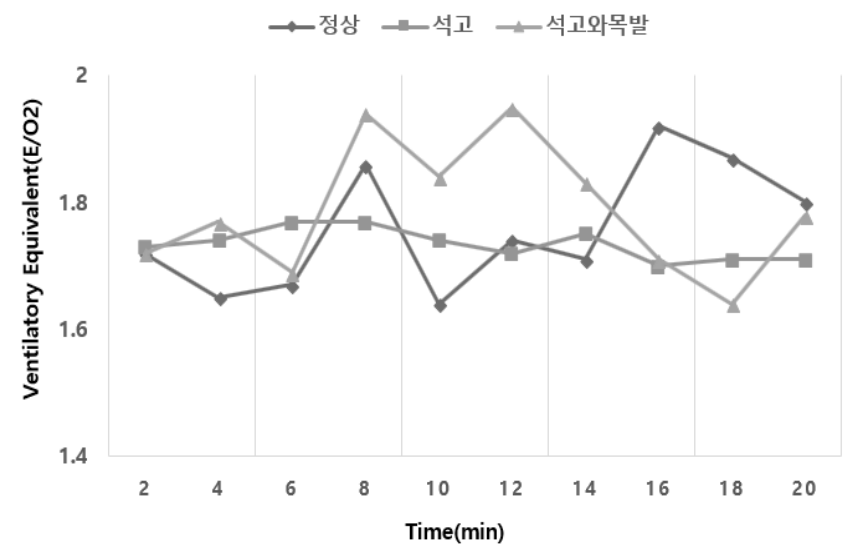

Figure 6. The changes of Ventilatory Equivalent

루어 볼 때 에너지 소모에 있어서 증가가 있을 것이라는 점을 짐작하게 해 준다. 본 연구에서 결정한 보행속도인 $3.62 \mathrm{~km} / \mathrm{h}$ 는 김미정 등 ${ }^{1)}$ 의 연구결과인 $4.08 \mathrm{~km} / \mathrm{h}$ 이나, $\mathrm{Kim}$ 등 $^{1)}$ 의 연구 결과인 $3.86 \mathrm{~km} / \mathrm{h}$ 보다는 느린 것이었다. 이는 본 실험의 대 상자들이 모두 남성이었으며 조건에 따른 제한과 트레드밀에 익숙하지 못한 결과라 생각된다. 황규성 등은 봏행속도는 심 리상태, 보행목적, 날씨, 기온, 몸 상태 등에 따라 영향을 받으 며 그 중 심리상태나 보행목적이 가장 큰 영향을 준다고 하였 다. 이런 점들을 미루어 볼 때 실험당시에는 보행에 대한 어떤 목적도 없었고 그렇게 급박한 심리상태도 아니었으므로 이러한 것들도 보행속도가 느린 것에 영향을 주었다고 생각해 볼 수 있다.

호흡교환율은 소모된 산소와 그로 인해 생산된 이산화탄소 의 비율을 말한다. 이는 운동 중에 에너지원으로 어떤 물질들 이 쓰이게 되었나 하는 것을 알 수 있게 해 준다. 호흡교환율 이 1 에 가까우면 탄수화물이, 0.71 에 가까우면 지방을 에너지 원으로 많이 동원하였음을 의미하며, 호흡교환율이 중간 수치 이면 탄수화물과 지방이 에너지원으로 같이 동원된다는 것을 의미한다." 운동강도가 약하거나 중간정도의 운동에서는 총 에 너지 소모의 30\% 50\%가 탄수화물로부터 이루어지는 반면에 $50 \% \sim 70 \%$ 가 지방으로부터 이루어진다. ${ }^{11)}$ 운동강도가 그 이상 일 때는 지방산이 에너지 공급원으로써 더 중요해지게 된다. ${ }^{10}$ 운동강도가 높고 운동시간이 짧은 경우에 탄수화물이 주 에너 지원으로 작용하지만 운동시간이 30 분 이상 지속되는 경우 점 차적으로 지방이 에너지원으로 차지하는 비율이 증가하게 된 다. ${ }^{11)}$ 본 연구에서는 호흡교환율이 대체적으로 0.86 에서 0.92 사이에 위치하고 있다. 이 같은 결과는 운동강도 계산에서도 알 수 있듯이 운동강도가 약하거나 중간정도의 수준에 해당하 는 것이며 지방보다는 탄수화물에 보다 치중하게 되는 수준이 라 볼 수 있다. 또한 각각의 조건들 모두가 운동시작 초기에 
비해 시간이 지남에 따라 호흡교환율 값이 줄어드는 경향을 보 인다. 이는 앞서의 연구결과들로 미루어 보아 운동시간의 경과 에 따른 상대적인 강도의 증가로 인한 결과라 생각된다. 그러 나 이러한 결과들이 통계학적으로 유의한 차이를 보이지는 않 았다. 또한 고강도 운동 후에는 산소소모량의 증가로 인해 전 체 칼로리 소모량의 증가가 높게 나타난다고 한다. ${ }^{11)}$ 본 연구 에서는 각 조건들이 칼로리 소모량에 있어서 운동 시작 초기나 후기를 비교해 볼 때 석고목발을 이용한 그룹만 차이가 있었 고, 정상군과 석고군의 경우는 거의 같은 수준의 칼로리 소모 를 보였다. 석고목발군은 다른 조건들에 비해 전반적으로 조금 씩 높기는 하였으나 이들 차이가 통계학적으로 유의하지는 않 았다.

본 연구에서 무릎관절에 석고를 착용한 군은 정상군과 비 교해서 볼 때 산소소모량, 호흡교환율, 환기량, 환기당량, 소모 칼로리에 있어서 차이가 있는 것처럼 보였으나 통계학적으로 유의하지는 않았다. 석고를을 착용하고 양손 목발보행을 실시 했을 때는 여러 측정인자들의 차이가 크게 나는 것을 볼 수 있 었다.

Edwin Hanada 등리 의 연구결과에서 한쪽 무릎관절 고정 군과 정상군을 비교해 볼 때 통계학적으로 유의한 차이를 보였 다. 이는 본 실험에서의 정상군과 석고군에 상응한다고 볼 수 있으나 본 연구에서의 실험결과와는 상반된 결과를 보인 것이 다. 이와 같이 다른 결과가 나온 이유는 보행속도와 보행교육 에서 차이를 보이기 때문이라고 생각한다. Edwin Hanada 등 ${ }^{12)}$ 의 실험에서 보행속도는 $3.31 \mathrm{~km} / \mathrm{h}$ 이고, 본 연구에서는 $3.62 \mathrm{~km} / \mathrm{h}$ 였다. 이것은 바로 에너지 소모의 차이가 있을 것임 을 말해 준다. 백일영ㄱㅇㅢ 연구결과를 보면 정상성인에 있어서 걷기의 속도가 증가함에 따라 산소소모량도 선형적으로 증가되 었으며 각각의 걷기 속도에 따른 산소소모량도 통계학적으로 유의한 차이를 보였다는 내용이 이것을 대변해 줄 수 있을 것 이다. 그리고, 보행교육에 있어서 본 실험에서는 석고군에 대해 그 보행에 대한 최적동작을 가르쳐 주고 그에 따르도록 하였 다. 그러나 Edwin Hanada 등 ${ }^{12)}$ 의 실험에 있어서는, 그런 내 용의 교육이 없었다는 부분을 대상작용의 다양함을 통해 알 수 있었다. 따라서, 이 두 가지 요인이 주로 작용하여 상반된 결과 를 얻게 되었다고 생각된다.

본 연구에서의 한쪽 무릎관절을 고정하고 양손 목발보행을 실시한 군과 Edwin Hanada 등 ${ }^{12}$ 의 한쪽 무릎관절과 동측 팔을 고정한 군은 정상군과 비교해 볼 때 에너지 소모에 있어 서 통계학적으로 유의한 차이가 있는 유사한 결과를 나타냄을 알 수가 있었다. 이는 목발사용이나 팔 고정이 무릎관절 고정 과 더불어 보행시에 일어나는 정상적인 동작을 제한하게 되며 이는 곧, 에너지 소모를 증가시키게 된다는 것을 짐작할 수 있 게 해준다. 한편, Edwin Hanada 등 ${ }^{12)}$ 의 연구결과에서는 한
쪽 무릎관절 고정군과 한쪽 무릎관절과 동측 팔을 고정한 군 사이에 에너지 소모에 있어서는 유의한 차이가 없다고 했는데, 이 같은 결과는 각 실험대상들이 제한에 대응해서 대상작용을 했기 때문이라고 말하고 있다. 이는 회복 가능성이 희박한 편 마비 환자나 절단환자, 골절환자 등에 있어서 대상작용을 촉진 시켜 준다면 에너지 소모는 어느 정도 줄여 줄 수 있다는 내용 임을 알 수 있게 해준다. 또한 Edwin Hanada 등 ${ }^{12)}$ 은 에너지 소모에 대한 팔 흔들기의 영향에 대해, 편안한 보행시나 저속 보행에서는 팔 흔들기가 에너지 소모에 영향을 주지 않지만, 속도가 빨라진다면 영향을 줄 것이라고 말하고 있다. 이 같은 내용은 그의 연구결과 중에서 정상군과 팔을 고정한 군 사이의 에너지 소모량 비교나 한쪽 무릎관절 고정군과 한쪽 무릎관절 과 동측 팔을 동시에 고정한 군 사이의 에너지 소모량 차이의 비교에서 통계학적으로 유의한 차이가 없음을 통해서 알 수가 있다.

본 연구에서 주목할 만한 점은 석고군과 석고목발군의 경 우이다. 단지 목발만 더 추가되었는데 석고·목발군의 에너지 소 모는 타 조건들과 비교해서 유의하게 증가한다는 점이다. 이는 추가된 2 개의 목발과 연관됨을 석고군의 결과를 통해 알 수가 있다. 우선 추가된 목발은 보행시 일어나게 되는 팔과 몸통 및 골반의 정상적인 움직임을 방해하게 된다. 팔 흔들기는 물론, 골반에서의 좌우측 방향과 위아래 이동에 영향을 주게 되며, 또한 손상 시 필요에 의해 유도될 수 있는 대상작용도 감소시 키게 되는 것이다. 다음으로 평상시와는 다른 신체의 움직임들 이 일어나게 된다. 다시 말해서 목발을 사용함으로 인해 다리 에서만 이루어져야 할 체중부하가 팔에서도 이루어지게 된다는 것이다. 이렇게 되면 체중부하에 익숙치 않은 관련된 근육들의 피로를 유발시키고 또한 에너지 소모도 증가시키게 되는 것이 다. 또 다른 이유로는 정상적이고 원활한 호흡이 제대로 이루 어지지 않을 것이라는 생각이다. 목발 사용으로 인해 몸통 위, 아래의 굽힘이 있을 것이며, 이는 정상적인 호흡에 영향을 줄 수 있으리라 짐작해 본다. 이런 여러 요인들로 인해 석고목발 군 에서만 유의한 에너지 소모 증가가 있었다고 사료된다.

한편 김봉옥 등 ${ }^{5}$ 은 정상 성인의 발목에 $1 \mathrm{~kg}$ 단위로 하중 을 부가하고 보행을 시킬 때, 에너지 소모도에 있어서 유의한 증가가 있다고 하였다. 본 연구에서도 착용한 석고의 무게가 평균 $1 \mathrm{~kg}$ 정도였다. 그러나 앞서 언급했던 대로 정상군과의 유의한 차이는 보이지 않았다. 이는 본 연구에서의 석고는 단 지 하중의 부가라는 것만이 아니라 무릎관절을 중심으로 다리 전체 고정의 역할도 있었기 때문에 하중의 분산이 있었으리라 생각한다. 이에 더하여 본 연구에서의 에너지 소모는 석고목발 군에서 알 수 있듯이 석고 이외의 다른 증가 요인이 있을 것으 로 생각해 볼 수 있다.

사고나 질병으로 인해 장기적이든 단기적이든 정상적인 움 
직임에 장애가 생기게 된다면 이는 곧 에너지 소모에 부정적인 영향을 미치게 될 것이다. 그러나 본 연구를 비롯해 앞서 행해 졌던 여러 연구결과들을 살펴볼 때 에너지 소모를 조금이나마 줄이는 방법들을 찾을 수 있을 것이라 생각해 본다. 이는 임상 에서 운동치료나 보행훈련 뿐만 아니라 기타 여러 물리치료 방 법들에서도 적용시킬 수 있다고 보며, 아울러서 이런 결과들의 임상적 적용이 이루어진다면 치료의 효과를 올리는데도 조금이 나마 도움을 줄 수 있을 것이라 사료된다.

\section{V. 결론}

본 연구는 대전지역 21 명의 건강한 남자를 대상으로 정상 보 행, 석고고정 보행, 석고고정 후 목발 보행을 통해 심폐기능의 변화를 알아보기 위하여 실시되었다.

연구결과 정상보행과 석고고정 보행 그리고 석고목발보행 은 에너지대사량에 차이가 있었다. 특히 석고고정 보행이 정상 보행과 큰 차이가 없었던 것에 비해 석고목발보행은 정상보행 과 석고고정보행에 비해 에너지대사량이 높게 나타났다. 본 연 구를 통해서 석고와 목발을 이용하는 환자들의 보행에 있어 석 고 고정만 사용했을 때보다 석고와 목발이 함께 사용되었을 때 더 큰 영향을 준다는 것을 알 수 있었다. 따라서 신경학적 문 제를 갖고 있는 편마비 환자나 발목 골절 등으로 제한된 부가 장치를 사용했을 때 폐기능을 고려하여 추가적인 운동 프로그 램이나, 석고 고정을 통해 발생될 수 있는 2 차적인 문제점이 발생되지 않도록 적절한 조치가 필요하다고 생각된다.

\section{References}

1. Kim MJ, Lee SA, Kim SK, et al. The study for gait speed of stroke patients comfortable versus maximum safe speed. Ann Rehabil Med. 1994;18(4):736-41.

2. Kim BO, Hong JY, Yoon SH. Energy cost during walking and usefulness of physiological cost index in hemiplegic patients. Ann Rehabil Med. 1996;20(1):39-44.

3. Yune SH, Byun JH. The cardiopulmonary responses on postural change and intensity of exercise, Chungnam Medical Journal. 1994;21(2):85-92.

4. Cha KS. New Exercise Proscriptions for Professionals. 21c Edu. 1999;35-36.

5. Kim BO, Chae SS, Kim YG, et al. Change of energy consumption according to loading on the ankle of normal adults during gait. J Kor Soc Phys Ther. 1999;11(2):43-9.

6. Kim JH, Han TR, Kwon YW. Oxygen consumption during activities of daily living in hemiplegia. Ann Rehabil Med.
1996;19(3):553-8.

7. Paik IY. Verifying walking efficiency by oxygen consumption during different walking speeds. J Kor Phys Education. 1995;34(3):233-47.

8. Hwang KS, Kim IJ, Bu JH. The determination of the optimum walking speed use of criterion to optimize energy expenditure. Dong-Eui Institute of Technology study. 1998;123-8.

9. Oh YS, Ha MS, Cho JY. Effect of resistance training and aerobic training on energy metabolites, hormone and excess post - exercise oxygen consumption. J Kor Phys Education. 2001;41(1):333-44.

10. Kim WJ. Effect of energy expenditure exercise in the cold environment. J Kor Phys Education. 2001;40 (2):623-33.

11. Oak JS, Kang CK, Choi BW. Energy metabolism and responses of stress to two selected methods of aerobic exercise. J Kor Exercise Science Academy. 1999;8 (3):323-34

12. Edwin H, Casey K. Energy consumption during level walking with arm and knee immobilized. Ach Phys med Rehabil. 2001;1251-4. 